\title{
Investigating geochemical factors affecting heavy metal bioaccessibility in surface sediment from Bernam River, Malaysia
}

\begin{abstract}
The present study applied the use of sequential extraction technique and simple bioaccessibility extraction test to investigate the bioavailable fractions and the human bioaccessible concentration of metals collected from nine stations in surface sediment of the Bernam River. The concentrations of total and bioaccessible metals from different stations were in the range of $0.30-1.43 \mu \mathrm{g} \mathrm{g}^{-1}$ and $0.04-0.14 \mu \mathrm{g} \mathrm{g}^{-1}$ for total cadmium and bioaccessibility of cadmium, respectively, $6.20-288 \mu \mathrm{g} \mathrm{kg}^{-1}$ and $2.06-8.53 \mu \mathrm{g} \mathrm{kg}^{-1}$ for total mercury and bioaccessibility of mercury, respectively, and $9.2-106.59 \mu \mathrm{g} \mathrm{g}^{-1}$ and $0.4-$ $2.75 \mu \mathrm{g} \mathrm{kg}^{-1}$ for total tin and bioaccessibility of tin, respectively. The chemical speciation of $\mathrm{Cd}$ in most sampling stations was in the order of oxidisable-organic $>$ acidreducible > residual > exchangeable, while the chemical speciation of $\mathrm{Hg}$ was in the order of exchangeable $>$ residual $>$ oxidisable-organic $>$ acid-reducible and the chemical speciation of $\mathrm{Hg}$ was in the order of residual > oxidisable-organic > acid-reducible > exchangeable. The principal component analysis showed that the main factors influencing the bioaccessibility of mercury in surface sediments were the sediment total organic matter, cation exchange capacity, and easily, freely, or leachable and exchangeable fraction, and the factors influencing the bioaccessibility of tin were the total tin and cation exchange capacity, while the bioaccessibility of $\mathrm{Cd}$ in surface sediments was influenced by the only factor which is the easily, freely, or leachable and exchangeable fraction.
\end{abstract}

Keyword: Bioaccessibility; Sediment; Hg; Cd; Bernam River 